\title{
Geocentrifuge Studies of Flow and Transport in Porous Media FINAL REPORT FOR \\ GRANT NUMBER DE-FG02-03ER63567 TO THE UNIVERSITY OF IDAHO (RW SMITH) Environmental Management Science Program Project Number 86598 Coupled Flow ANd Reactivity in Variably Saturated Porous Media
}

\section{June 2007}

\author{
Principal Investigator \\ Carl D. Palmer \\ Idaho National Laboratory \\ Idaho Falls, ID 83415 \\ (208) 526-4478 \\ carl.palmer@inl.gov
}

\author{
Co-Principal Investigators \\ Earl D. Mattson \\ Idaho National Laboratory \\ Idaho Falls, ID 83415 \\ (208) 526-4084 \\ earl.mattson@inel.gov
}

\author{
Robert W. Smith \\ University of Idaho-Idaho Falls \\ Idaho Falls, ID 83402 \\ (208) 282-7954 \\ smithbob@uidaho.edu
}

\begin{abstract}
Improved models of contaminant migration in heterogeneous, variably saturated porous media are required to better define the long-term stewardship requirements for U.S. Department of Energy (DOE) lands and to assist in the design of effective vadose-zone barriers to contaminant migrations. The development of these improved models require field and laboratory results to evaluate their efficacy. However, controlled laboratory experiments simulating vadose conditions can require extensive period of time, and often are conducted at condition near saturation rather than the much drier conditions common in many contaminated arid vadose zone sites. Collaborative research undertaken by the Idaho National Laboratory (INL) and the University of Idaho as part of this Environmental Management Science Program project focused on the development and evaluation of geocentrifuge techniques and equipment that allows vadose zone experiments to be conducted for relevant conditions in time frames not possible in conventional bench top experiments. A key and novel aspect of the research was the use of the 2-meter radius geocentrifuge capabilities at the Idaho National Laboratory to conduct unsaturated transport experiments. Specifically, the following activities were conducted
\end{abstract}


- Reviewing of the theory of unsaturated flow in the geocentrifuge to establish the range of centrifuge accelerations/experimental conditions and the translation of centrifuge results to 1 gravity applications.

- Designing, constructing, and testing of in-flight experimental apparatus allowing the replication of traditional bench top unsaturated transport experiments on the geocentrifuge.

- Performing unsaturated 1-dimenstional column geocentrifuge experiments using conservative tracers to evaluate the effects of increased centrifugal acceleration on derived transport properties and assessing the scaling relationships for these properties.

Because the application of geocentrifuge techniques to vadose transport is in its infancy experimental apparatus such as pumps, flow meters, columns, fraction collectors, etc. that would reliably function under the increased self weight experienced on the centrifuge had to be developed and tested as part of this project. Although, we initially planed to conduct experiments using reactive tracer and 2-dimensional heterogeneities, the cost and time associated with designing, building, and testing of experimental apparatus limited our experimental program to conservative tracer experiments using 1-dimensional columns.

The results we obtained in this study indicate that the geocentrifuge technique is a viable experimental method for the study of subsurface processes where gravitational acceleration is important. The geocentrifuge allows experiments to be completed more quickly than tests conducted at 1-g, can be used to experimentally address important scaling issues, and permits experiments under a range of conditions that would be difficult or impossible using conventional approaches. The application of the geocentrifuge approaches and associated models developed in this project allows more meaningful investigation of DOE relevant vadose-zone issues under scalable conditions in time frames previously not obtainable. 


\section{Geocentrifuge Studies of Flow and Transport in Porous Media}

Final Report

Environmental Management Science Program Project Number 86598

Coupled Flow and Reactivity in Variably Saturated Porous Media

\section{June 2007}

\author{
Principal Investigator \\ Carl D. Palmer \\ Idaho National Laboratory \\ Idaho Falls, ID 83415 \\ (208) 526-4478 \\ carl.palmer@inl.gov
}

\section{Co-Principal Investigators}

Earl D. Mattson
Idaho National Laboratory
Idaho Falls, ID 83415
(208) 526-4084
earl.mattson@inel.gov

\author{
Robert W. Smith \\ University of Idaho-Idaho Falls \\ Idaho Falls, ID 83402 \\ (208) 282-7954 \\ smithbob@uidaho.edu
}

\section{Introduction}

The nature and extent of DOE subsurface environmental problems are widely recognized. The selection of and design of subsurface environmental restoration strategies (including monitored natural attenuation) for these problems rely on the uses of sophisticated numerical models that couple transport and biogeochemical processes to predict the fate and transport of contaminants and introduced remediation agents in heterogeneous subsurface media. These models are typically validated by comparing modeling results to 'small-scale' laboratory and 'large-scale' field research demonstrations. Although controlled field experiments have the advantage of being representative of the field-scale problem, these experiments are costly, difficult to perform, limit the use of relevant contaminants, and offer little direct control over boundary conditions. Conversely, laboratory column experiments, which are generally inexpensive and relatively easy to conduct, are of limited value because they do not mimic field conditions. These limitations are compounded in vadose zone studies because of the length of time (up to 300 days per experiment, Jardine et al. 1993a, b) required to conduct unsaturated reactive transport column experiments. Experimental data obtained from 'intermediate-scale' centrifuge tests could assist in optimizing field demonstration designs and interpretations, and facilitate the evaluation of multiple experimental realizations to assess critical information on the 
transport and biogeochemical reactions

needed for model validation and scale-up remedial actions.

Centrifuge scaling laws have been established for geotechnical applications and have been used to scale field processes to sizes that can be managed on large geocentrifuges. These scaling laws are based upon a ratio of the magnitude of centrifugal acceleration generated by the geocentrifuge to the gravitational acceleration on earth. Typically, scaling relationships are specified in terms of $\mathrm{N}$, the centripetal acceleration (given as $\omega \mathrm{R}^{2}$ where $\omega$ is the angular rotational speed and $\mathrm{R}$ is the radius of the centrifuge experiment) in centrifuge (in $\mathrm{m} \mathrm{s}^{-2}$ ) divided by the gravitational acceleration (9.8 $\mathrm{m} \mathrm{s}^{-2}$ ). Through these scaling relationships, geotechnical engineers have used small scaled-models (scaled in both time and size) of engineered systems in geocentrifuge experiments to examine a variety of full size (referred to as the prototype) field-scale geotechnical issues such as earthen dam integrity, to a buildings' structural response to earthquakes. A summary of the common scaling relationships is given in Table 1 (Culligan and Savvidou 1995). Note that the relationships given in Table 1 are those required for complete similitude between a centrifuge experiment ( $\mathrm{N} \mathrm{x} \mathrm{g)} \mathrm{and} \mathrm{its} \mathrm{bench} \mathrm{top}$ counterpart. In most experiments, it is not possible to simultaneously satisfy all the scaling relationships. For example, if the same geomedia and chemical constituents are used in a centrifuge and bench top experiment, the decay rate for both will be the same rather than scaled by $1 / \mathrm{N}^{2}$.
Field:

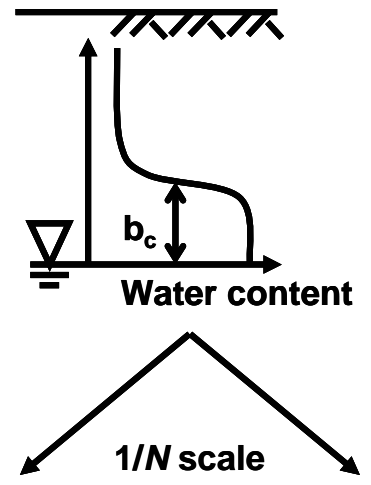

1g model:

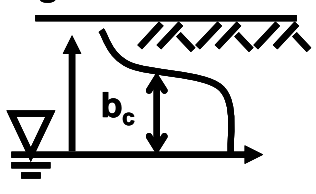

Figure 1. Schematic showing the scaling relationship for a centrifuge model of a water table capillary fringe. In a given material at field-scale, water rises against gravity to a height of $b_{c}$ above the water table due to capillary force. If a laboratory model (subject to earth gravity) is constructed, the capillary rise in the model is also $b_{c}$. However, if the model is subjected to centrifugal acceleration simulating $\mathrm{N}$ time earth gravity, the height of the capillary rise is $b_{c} / N$. 
The importance of sizescaling in geo-environmental centrifuge application is presented conceptually in Figure 1. In this figure, the vadose zone saturation state is shown for profile above the water table. The height of the capillary fringe, $b_{c}$, in the field case is determined by the balance of the gravitational and capillary forces acting on the water. In bench-top experiments with the same soil, the capillary rise should be the same as the field case. This
Table 1. Centrifuge Scaling Factors for correct similitude modeling (after Culligan and Savvidou 1995).

\begin{tabular}{lcc|} 
Parameter & Symbol & $\begin{array}{c}\text { Prototype-model } \\
\text { ratio }\end{array}$ \\
\hline Gravity & $\mathrm{g}$ & $1 / \mathrm{N}$ \\
Length & $\mathrm{z}$ & $\mathrm{N}$ \\
Pressure & $\mathrm{p}$ & 1 \\
Temperature & $\mathrm{T}$ & 1 \\
Solute Mass Fractions & $\mathrm{w}$ & 1 \\
Density & $\rho$ & 1 \\
Viscosity & $\mu$ & 1 \\
Porosity & $\mathrm{n}$ & 1 \\
Velocity & $\mathrm{v}$ & $1 / \mathrm{N}$ \\
Time & $\mathrm{t}$ & $\mathrm{N}^{2}$ \\
Dispersion Coefficient & $\mathrm{D}$ & 1 \\
Linear Decay Rate Constant & $\lambda$ & $1 / \mathrm{N}^{2}$ \\
\hline
\end{tabular}

result could present some difficulties if the soils are fine-grained. Under these conditions the capillary rise may be in excess of a meter and this could dictate the minimum column length if one were investigating unsaturated flow and transport with a free drainage boundary. In the centrifuge model the capillary forces are balanced by the centripetal force. If the angular acceleration is such that the centripetal force is $\mathrm{N}$ times greater than the gravitational acceleration, then the capillary rise will be $b_{c} / N$. In principle, this means that the sample size could be approximately $1 / \mathrm{N}$ times the size of the 1 -g bench-scale experiments. This scaling allows the investigation of fluid/solute movement and moisture distribution for complex vadose zone heterogeneities representative of field setting in smaller well controlled experiments.

Additionally, the geocentrifuge can be used as a tool to examine the fate and transport of water and solutes in geologic media. In these situations, the results are typically scaled by increase advection of water through the sample allowing the scaling of the time for a onedimensional analysis; a solute transport experiments that would takes a year to conduct on the bench top can be completed in a week in a geocentrifuge operating at 50-gs.

Although commercially available cabinet size centrifuges (Conca and Wright 1990, 1998, Gamerdinger and Kaplan 2000) are used in vadose zone research, their application is limited to 
small samples (5.2 cm length x $3.3 \mathrm{~cm}$ diameter or $\sim 45 \mathrm{~cm}^{3}$ ) of homogeneous materials. These small centrifuges also exert a non-uniform centrifugal acceleration across the length of the sample. A general rule of thumb used in geotechnical engineering is that the sample should not be greater that $20 \%$ of the centrifugal radius (Taylor 1995). Most small centrifuges violate this rule resulting in variable acceleration forces being applied along the length of the sample. In addition, the upper boundary is limited to flux controlled (either a specified flux or no flux) while the lower boundary is limited to a free drainage boundary condition. Because of the lack of in-flight monitoring of moisture contents, pressures and solute concentrations, measurement of these variables are physically acquired after stopping the centrifuge.

Large centrifuges overcome many of the limitations of bench-top centrifuges in conducting environmental restoration research analysis. Advantages of large centrifuges include large sample size (both in diameter and length), better experimental control of the boundary conditions, in-flight monitoring of the state variables, and multi-dimensional testing. Geocentrifuge systems allow the conduct of "bench-scale” type experiments under enhanced accelerations with full automation control of the experiment. We have used the INL geocentrifuge to investigate solute transport in one-dimensional column experiments over a range of centrifugal acceleration. In addition, we have conducted a theoretical assessment (summarized in Appendix A) of unsaturated fluid flow in geomedia subjected to a combination of gravitational and centrifugal acceleration (Palmer et al. 2003, 2005, in prep).

\section{Idaho National Laboratory-Geocentrifuge Facility}

The Idaho National Laboratory Geocentrifuge Research Facility is located in Idaho Falls, Idaho, in the Bonneville County Technology Center. The 200- $\mathrm{m}^{2}$ centrifuge high-bay laboratory houses the INL 2-m radius, 50 g-tonne Actidyn Systemes model C61-3 centrifuge (Figure 2) and has an asymmetric beam equipped with a pendulum swinging basket that rotates within a cylindrical steel and reinforced concrete enclosure. The centrifuge can carry an experimental package as large as $70 \mathrm{~cm}$ long by $50 \mathrm{~cm}$ thick by $60 \mathrm{~cm}$ high and $500 \mathrm{~kg}$ mass The centrifuge control center provides fully automated operation of the centrifuge allowing precise control of rotational speeds of up to 260 revolutions per minute providing centrifugal acceleration up to 130 $\mathrm{g}$ at the nominal radius of the centrifuge (Smith et al. 2002). An experimental package is built in a cage-like aluminum support structure that both supports the experiment and provides secondary 
containment in case of leakage or failure. The package is placed on the centrifuge platform and is connected to the data acquisition system, electrical power, and vacuum system. As the centrifuge is spun, the platform that is hinged on the centrifuge arm will respond to the centrifugal acceleration and begin to rotate outward towards the centrifuge wall at an angle that balances earths gravitational acceleration and the centrifugal acceleration. In this manner, the net acceleration experienced by the experimental package will always be nearly normal to centrifuge platform.

In-flight experimental control and monitoring of experiments are accomplished using a data acquisition system employing a wireless hub linking computers in the control room with National Instruments data acquisition

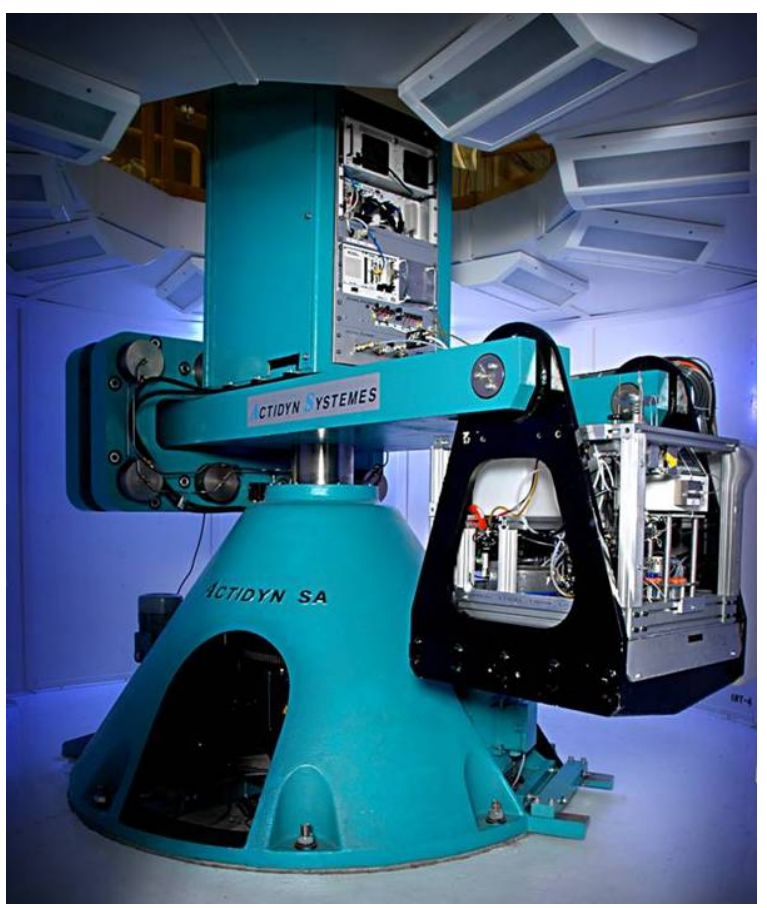

Figure 2. The Idaho National Laboratory 2-meter radius computer controlled Actidyn model C-61-3 geotechnical centrifuge with solute transport experiment installed on its "swingingbucket” platform. systems mounted on the rotating centrifuge. Real-time monitoring data is collected and displayed using LabView software, transmitted to the control room computers and can be accessed via the web by collaborating researchers. Auxiliary experimental equipment includes a full soil characterization laboratory specializing in measuring unsaturated flow and transport properties of porous media including an unsaturated flow apparatus (UFA) centrifuge. The remainder of the high-bay laboratory is used for model preparation and includes a machine shop to assist in the construction of models.

\section{Methods}

Soil Columns - The granular material used in the column experiments was obtained adjacent to the INL CERCLA Disposal Facility (ICDF) near the Idaho Nuclear Technology and Engineering Center (INTEC) tank farms. Sufficient soil was collected at the beginning of the project to support all experiments. The soil was dry sieved to remove material larger than $2 \mathrm{~mm}$ and wet sieved to remove materials less than $0.075 \mathrm{~mm}$. A final rinse with ultra-pure water 

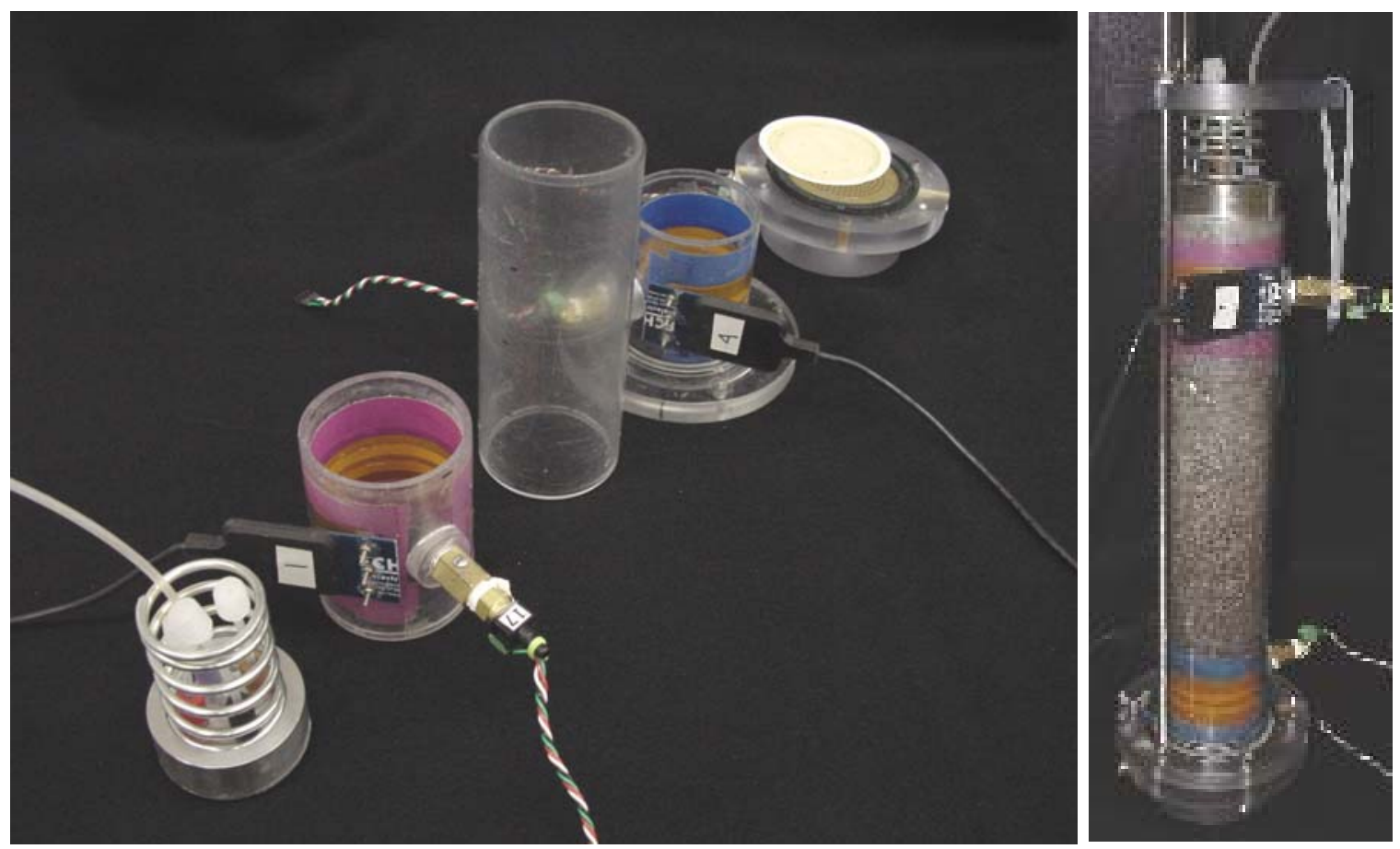

Figure 3. Multi-piece Lexan column used for 1-dimensional solute transport experiments. Key features of the columns are the installed capacitance water content probes and the mini tensiometers.

( $18 \mathrm{M} \Omega$ ) was performed to remove excess salts and then the media was oven dried for 24 hours. The soil was weighted and then wetted to the target water content with $330 \mathrm{ppm} \mathrm{KBr}$ solution, mixed well, and packed into a $5.7 \mathrm{~cm}$ diameter by $28 \mathrm{~cm}$ long multi-piece Lexan test column (Figure 3). At the top of the test column, a floating cap with a porous stone disk was used to spread the input solution over the surface of the column. The upper cap was not rigidly attached to the column but was pressed against the soil surface using a large compression spring to ensure good contract during the experiment. The moisture content and matric potential were monitored in the soil column at two locations approximately $4.5 \mathrm{~cm}$ from each end. Soil moisture was measured using a modified Decagon Echo 10 probe where the electrodes have been modified to wrap around the inner circumference of the experimental column (Mattson et al. 2006). Small diameter $(0.5 \mathrm{~cm})$ porous ceramic cups are attached to Honeywell 26PCCFA6D pressure transducers ( 0 to 15 psi range) to measure the soil matric potential. The lower boundary was designed as a constant pressure boundary using a Versapor 1.2 um diameter filter supported by a porous stone between the soil and the lower fluid collection chamber. A constant vacuum was applied to the lower fluid collection chamber. 


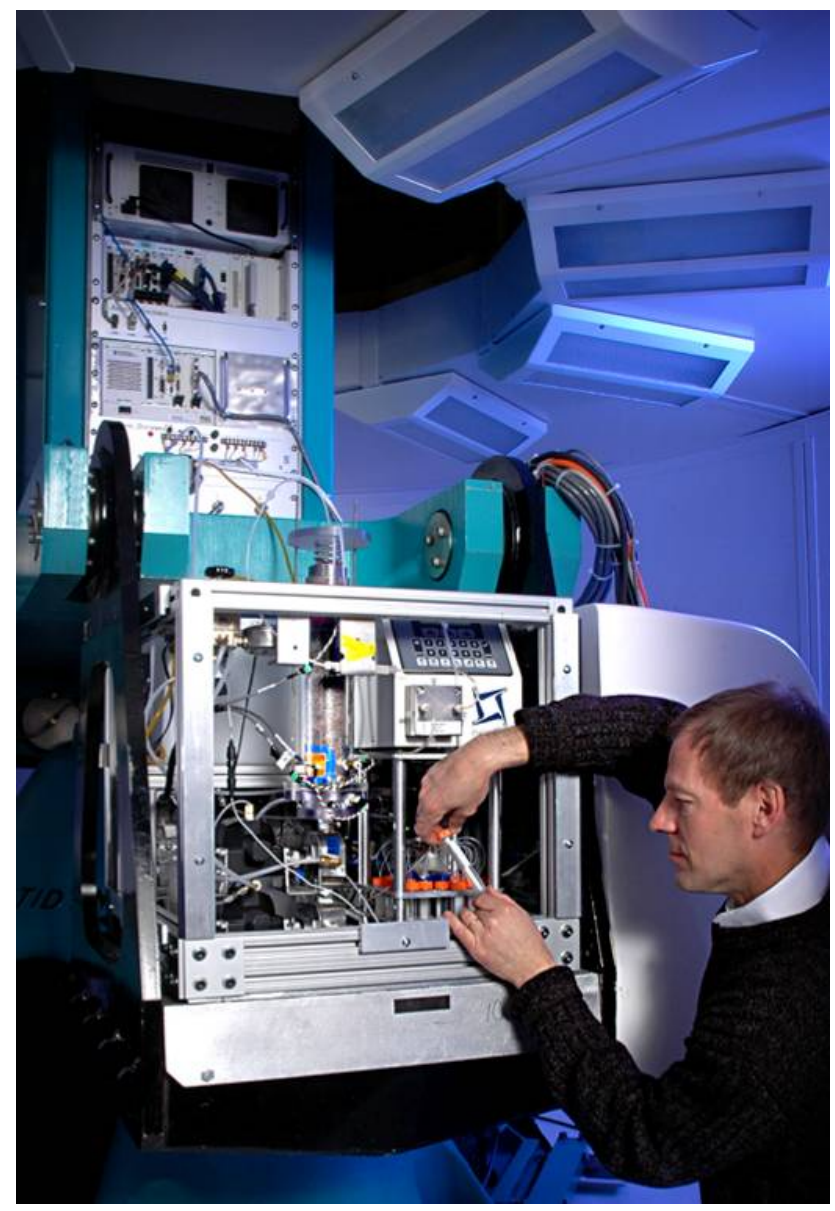

Figure 4. Experimental package installed on the platform of the INL 2-meter centrifuge. Note the column (center), solute tank (upper left), pump (upper right), and effluent sampling system (lower right).
The experimental package (Figure 4 and 5) consists of an apparatus that controls the type of solution and the rate of application to the surface of a soil column, the soil column and its associated monitoring devices, an effluent sampling system, and a effluent waste container that is maintained under a vacuum. Two tanks under atmospheric pressure contain a $330 \mathrm{ppm} \mathrm{KBr}$ background solution and a 2000 ppm KBr tracer solution. A solenoid 3way valve controls which of the solutions is pumped to the column. A remotely controlled Encynova pump (model 2-4) is used to adjust the flow rate to the top of the soil column while the centrifuge is spinning. An experiment is conducted by placing the experimental package on the centrifuge platform and spinning the centrifuge at a constant speed to obtain the desired centrifugal acceleration on the experiment. The 3-way valve is set to the $330 \mathrm{ppm} \mathrm{KBr}$ background solution and a constant flux is delivered to the top of the column via the pump. A constant vacuum is applied to the effluent collection system at the base of the soil column. The vacuum is adjusted until the monitoring equipment (capacitance probes and tensiometers) indicates that the soil column is in steady state. At this time, the 3-way valve is switched to the $2000 \mathrm{ppm} \mathrm{KBr}$ tracer solution and the fraction collector is activated to collect discrete effluent samples at a predetermined time intervals.

The experiment is remotely controlled and monitored using computer programs written using LabView software. LabView controls the 3-way valve switching of the influent background and tracer application, the pump rate, and the effluent collection system. Monitoring of the experiment is also accomplished using the LabView program. Influent water flow rate, 


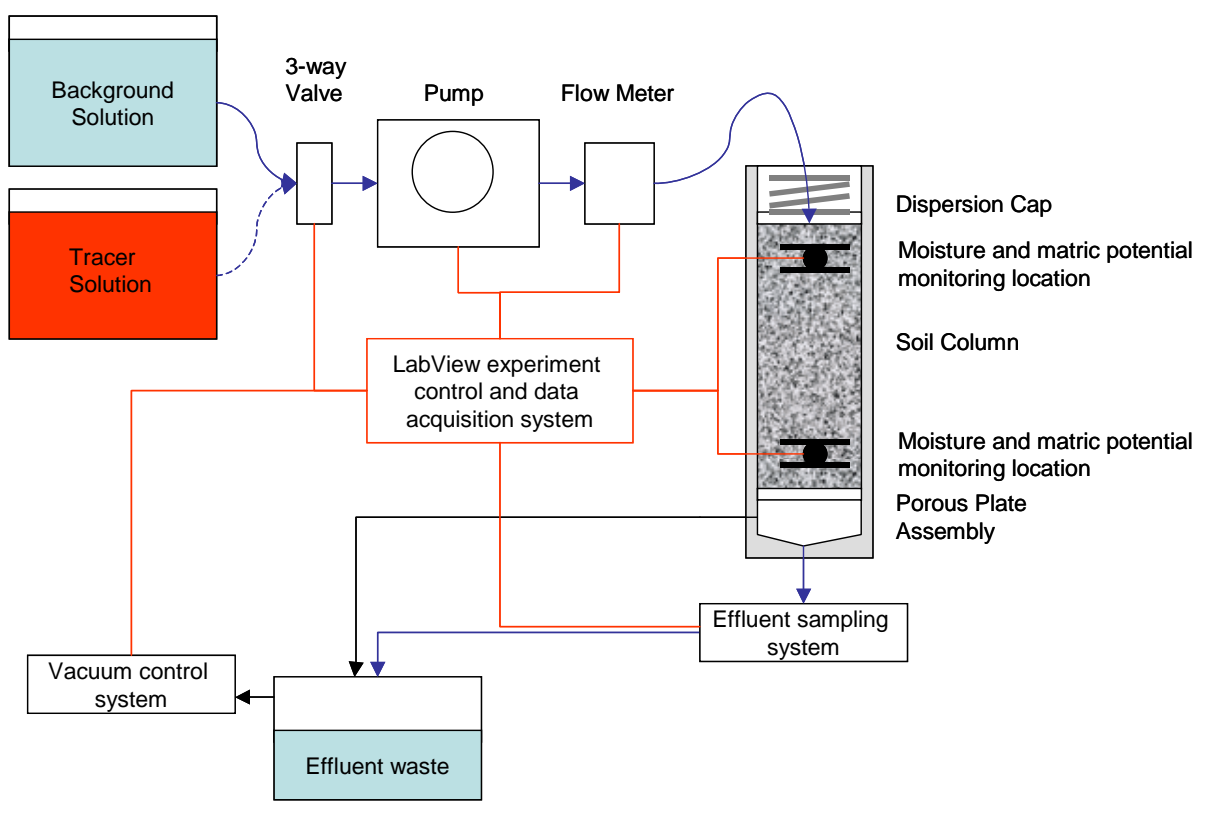

Figure 5. Schematic illustrating the major components of solute transport through unsaturated porous media experimental setup.

soil moisture, soil matric potential, applied vacuum at the lower boundary, and the effluent electrical conductivity can be monitored at any user-specified interval. Influent flow rates are recorded using a Sensirion ASL-1430-24 liquid mass flow meter capable of recording flow levels as low as $150 \mathrm{~nL} \mathrm{m^{-1 }}$. The lower boundary vacuum is controlled outside of the centrifuge by adjusting the pressure of air being supplied through the centrifuge rotary joint to a venturi vacuum pump (Cole-Parmer) mounted on the rotating centrifuge. The vacuum is monitored using a Honeywell pressure transducer (26PCCFA6D [0 to 15 psi range]). Electrical conductivity of the effluent solution was measured using a Microelectrode (model 16-900) flowthru conductivity electrode. Because commercially available fraction collectors would not operate on the geocentrifuge, fluids samples were collected using an effluent sampling system designed and built as part of this project. A fundamental difference between our sampling system and commercially available fraction collectors is the reliance on valves and air pressure to move fluids to stationary sample vials rather that attempting to move the sample vials.

Column effluent is allowed to fill a sample accumulation connection tube between two large-bore stainless steel 3-way valves (Figure 6). Once the valve connection tube is full of effluent, excess effluent is allowed to flow into a waste container. To collect a sample, both 


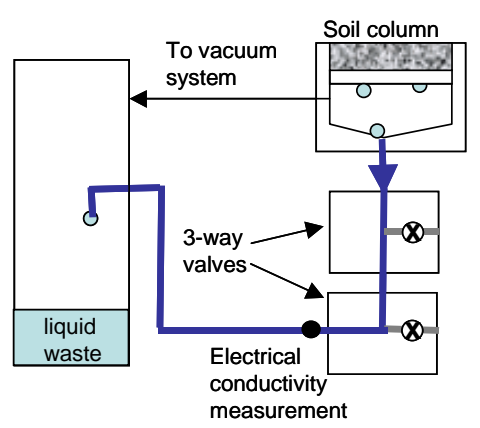

A) Valves position in accumulation mode

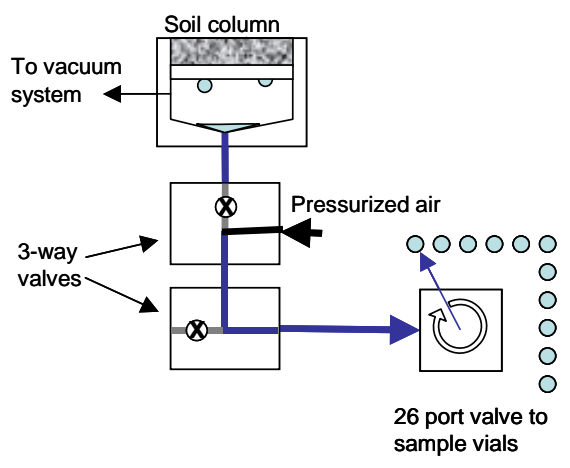

B) Valves position in sample collection mode

Figure 6. Schematic of the geotechnical centrifuge effluent collection system.

valves are activated (B position). When in the B position, the top valve isolates the column from the effluent collection chamber and the bottom valve isolates the collection tube from the waste container. Pressurized air is used to transport the effluent in the collection tube to a 26 port switching valve connected to $15 \mathrm{ml}$ sample collection vials (Figure 7). While the valves are switched in the ' $\mathrm{B}$ ' position, effluent from the column is allowed to accumulate above the upper 3-way valve. After a sufficient time has passed to empty the accumulation tube, the valves switch back to their original position to accumulate the next sample. Valve switching is automated through the LabView program allowing autonomous operation of the effluent collection for subsequent laboratory analyses. Timing of the sample collection is operator controlled. Multiple 26 port switching valves may be daisy-chained together to allow additional samples to be collected. The bromide concentrations of the effluent

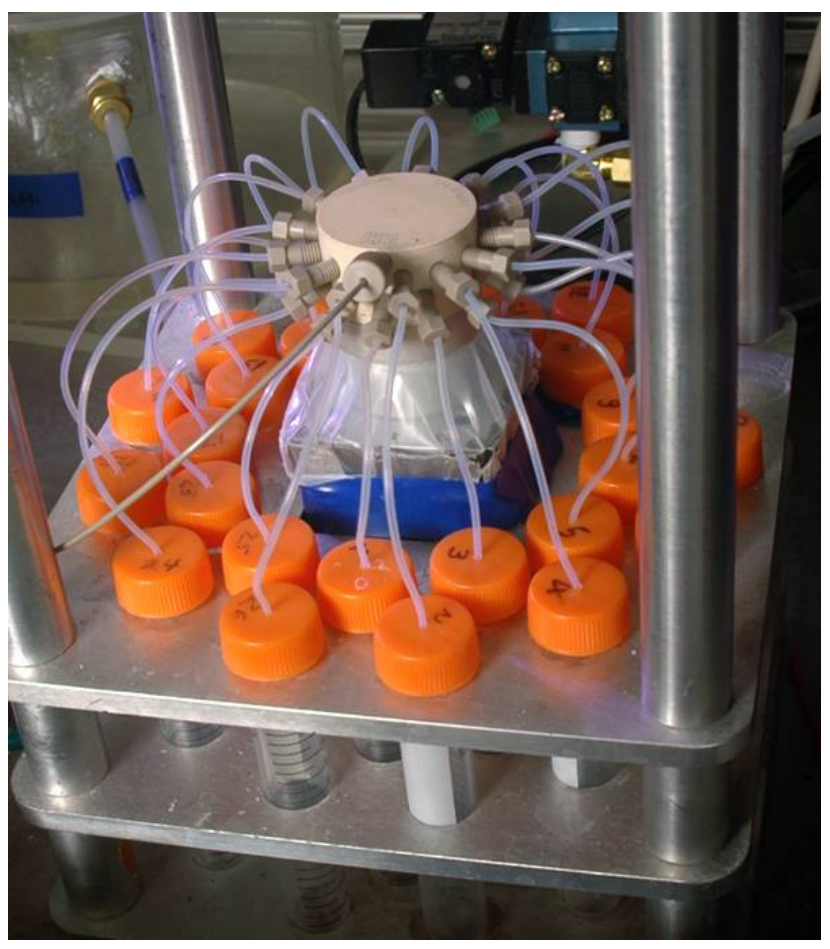

Figure 7. Effluent collection system (also shown schematically in Figure 6) for geocentrifuge solute transport experiments. Note the 26 position high pressure rotor valve (center). 
samples were determined using a model Dionex DX-320 ion chromatograph.

Experiments were conducted on the INL geocentrifuge at 10, 20, 30, and 40 times earth's gravitational acceleration. We attempted to establish consistent moisture contents in each of the experiments. The vertical advection of water through a soil is dependent on the body force experienced by the water. Therefore, due the change in the centrifugal acceleration on the experiment, the flux rate was change proportionally (1.4 to

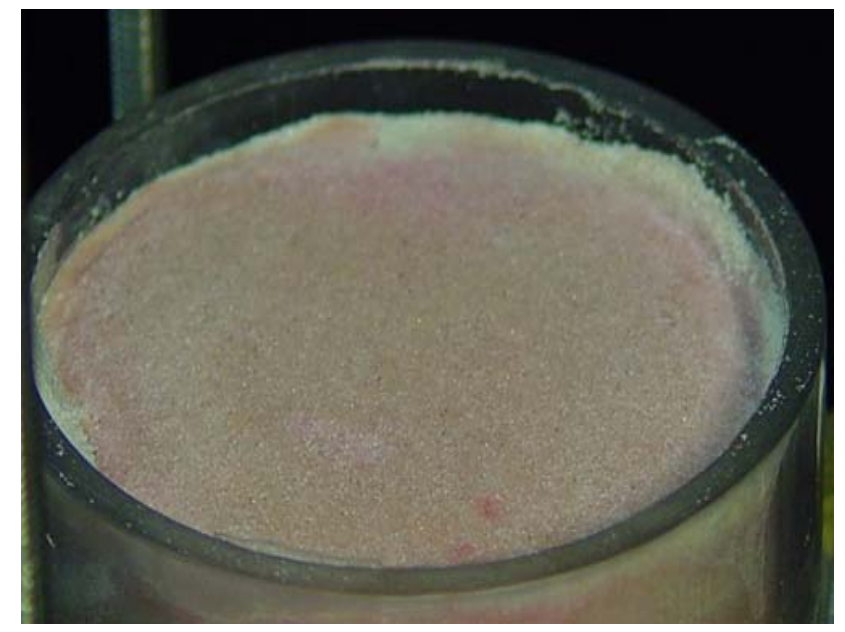

Figure 8. Uniform distribution of red dye demonstrates even spread of influent across to the top of the soil column.

$5.6 \mathrm{~mL} \mathrm{~min}^{-1}$ ) to the applied centrifugal acceleration in an attempt to balance the increased flux with the capillary forces of the soil.

\section{Results and Discussion}

A series of experiments were conducted in order to test the equipment and to verify the assumptions. The experiments were designed as one-dimensional column. This assumption was experimentally verified in equipment testing experiments. The experimental column has a specially designed dispersion cap that is spring loaded to maintain contact with the soil in the event of shrinkage or compression. An experiment was conducted to confirm that onedimensional flow was occurring in homogeneous packed sand. Visual analysis of an applied red dye tracer (Figure 8) in 110 mesh quartz sand confirmed that there is sufficient capillary dispersion in the porous stone to evenly spread the influent across the top of the soil. Subsequent destructive sampling of the column indicated an even red staining of the sand throughout the column.

An equipment test was conducted to evaluate the comparability of solute breakthrough curves determined by the in-flight electrical conductivity cell and post experimental analysis of bromide concentration. There is good correspondence between the breakthrough curves derived from the conductivity measurements and those determined by direct post experimental analysis 


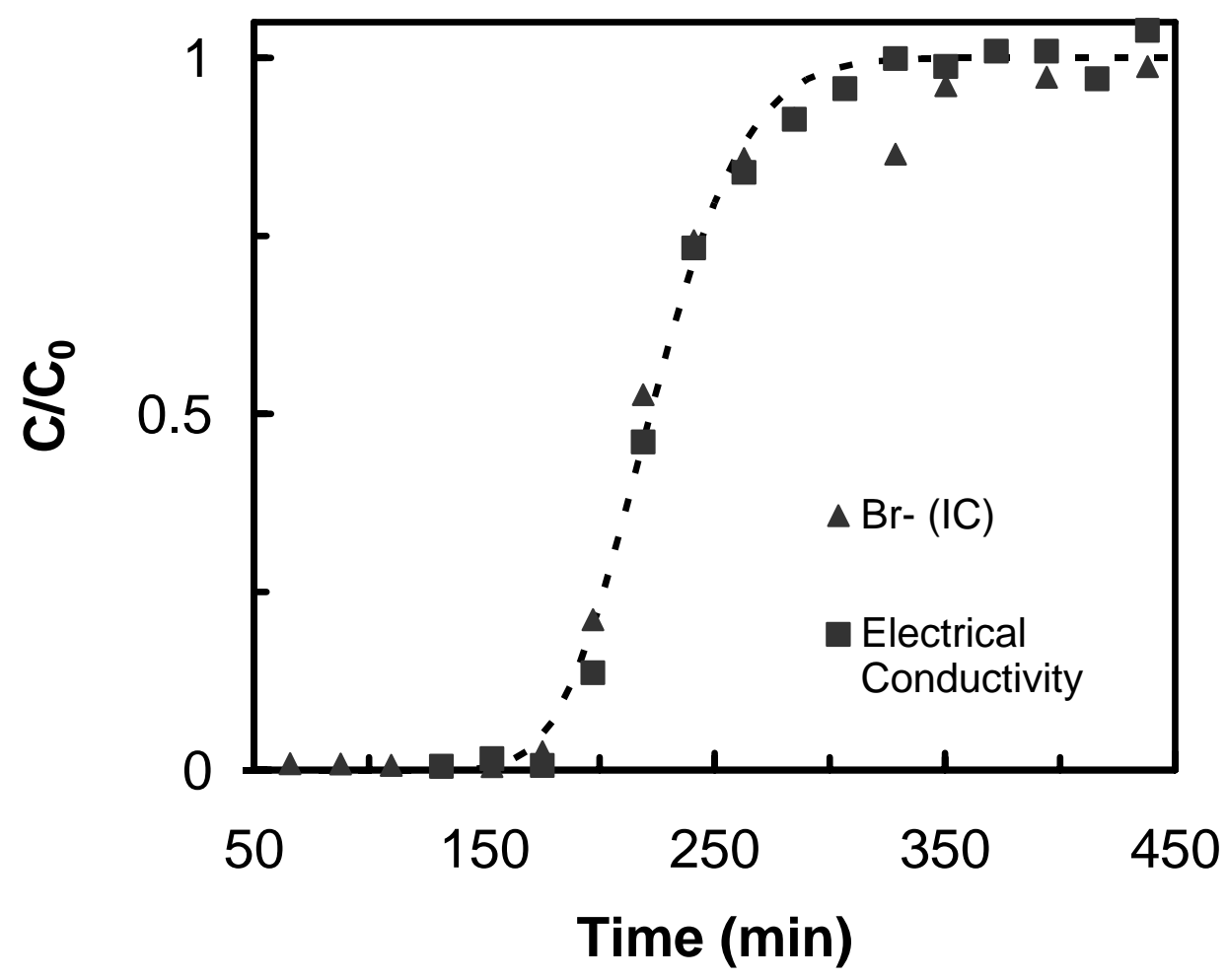

Figure 9. Breakthrough curve showing the correspondence between real time in-line electrical conductivity measurements and postexperimental analyses of $\mathrm{Br}^{-}$by ion chromatography.

of collected effluent samples (Figure 9). A single value for the velocity $\left(0.13 \mathrm{~cm} \mathrm{~min}^{-1}\right)$ and the dispersion coefficient $\left(0.040 \mathrm{~cm}^{2} \mathrm{~min}^{-1}\right)$ were estimated using a non-linear parameter estimation spreadsheet program and an analytical solution to the convection-dispersion (model) equation (CDE) (Wraith and Or 1998). The breakthrough curve calculated from these values describe both the normalized bromide effluent samples and the normalized in conductivity measurements. This result suggests that for the experiments involving only a $\mathrm{KBr}$ tracers described in this report, that breakthrough curves derived from the easier to collect continuous electrical conductivity measurements are reflective of breakthrough curves collected using the effluent sampling system and that breakthrough curves can be defined solely from the in-line conductivity measurements. However, experiments (not shown or discussed here) using multiple reactive and conservative tracers would require the use of the effluent sampling system and subsequent post experimental chemical analysis. 
One of the benefits of using a geocentrifuge for unsaturated solute transport experiments is that the time required to conduct an experiment can be decreased. Comparison of breakthrough results from two early experiments conducted on the geocentrifuge at $1 \mathrm{~g}$ and $20 \mathrm{~g}$ may be seen in Figure 10a. The 20-g experiment required significantly less time to achieve breakthrough $\left(\mathrm{C} / \mathrm{C}_{0}=0.5\right)$ when compared with the 1-g experiment. However, when the time of the two experiments are normalized using the applied flux and the column moisture content and plotted in terms of pore volume (Figure 10b) both exhibit similar breakthrough curves. The moisture content of the 20-g experiment was greater than the 1-g experiment and resulted in less dispersion in the 20-g experiment as compared to the $1 \mathrm{~g}$ experiment.

The normalized breakthrough curves for experiments conducted at 10, 20, 30, and $40 \mathrm{~g}$ respectively are shown in Figure 11. The average pore-water velocity, dispersion coefficient, moisture content and breakthrough time ( $\mathrm{t}$ for $\mathrm{C} / \mathrm{C}_{0}=0.5$ ) calculated from these breakthrough curves using a non-linear parameter estimation spreadsheet program (Wraith and Or 1998) are presented in Table 2. The flow rate through the column (also presented in Table 2) was adjusted based on a simple linear scaling with $g$ in an attempt to maintain the same water content in all experiments. Although mostly successful, the measured water content of the column illustrated a decreased with increasing $\mathrm{N}$, likely due to non-linear competition between gravitational (scaled in centrifuge experiments) and capillary (not scaled in centrifuge experiments) forces.

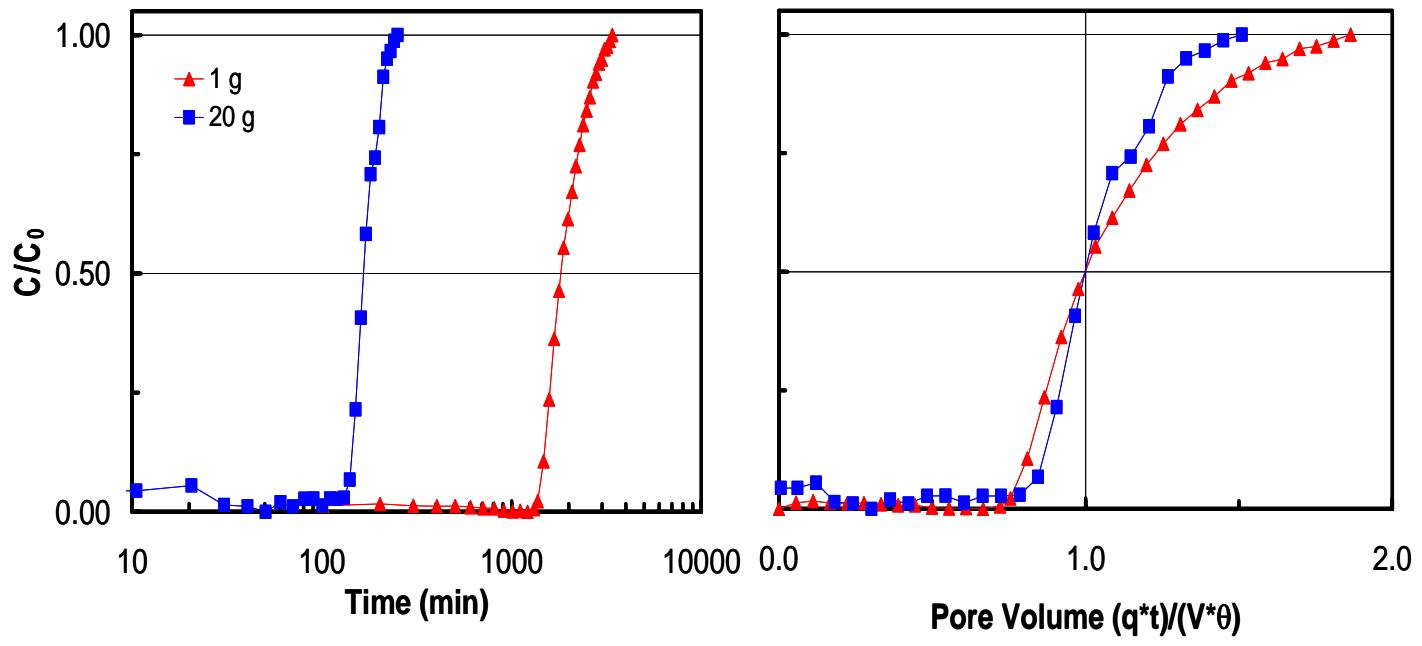

Figure 10. Comparison of breakthrough curves for 1-g and 20-g column experiments in terms of experimental time (left, 10a) and pore volume (right, 10b). 
As may be seen in Figures 12 and 13 , the time of arrival of the $\mathrm{C} / \mathrm{C}_{0}=0.5$ relative concentration at the effluent end of the column increases linearly with $1 / \mathrm{N}$ while the velocity increases with $\mathrm{N}$. Although the variability of water content in the column tests is relatively small (0.102 to 0.145 , Table 2$)$, there is a systematic variation with $\mathrm{N}$ (Figure 14). Since the hydraulic conductivity is a function of the volumetric water content and the moisture content is not exactly the same between the experiments, the transport results do affect some of the scaling relationships. For example, the time for the breakthrough at $\mathrm{N}=10$ is not exactly twice the time for breakthrough at $\mathrm{N}=20$ (see Table 2). Such deviation from simple scaling laws obtained in these unsaturated flow experiments would not be observed in saturated experiments where the hydraulic conductivity is constant.

The dispersion coefficient, increases nonlinearly with N (Figure 15) and appears to vary with the $\mathrm{N}^{2}\left(\mathrm{r}^{2}=0.997\right)$. This result is consistent with the scaling of dispersion with $\mathrm{N}$ reported

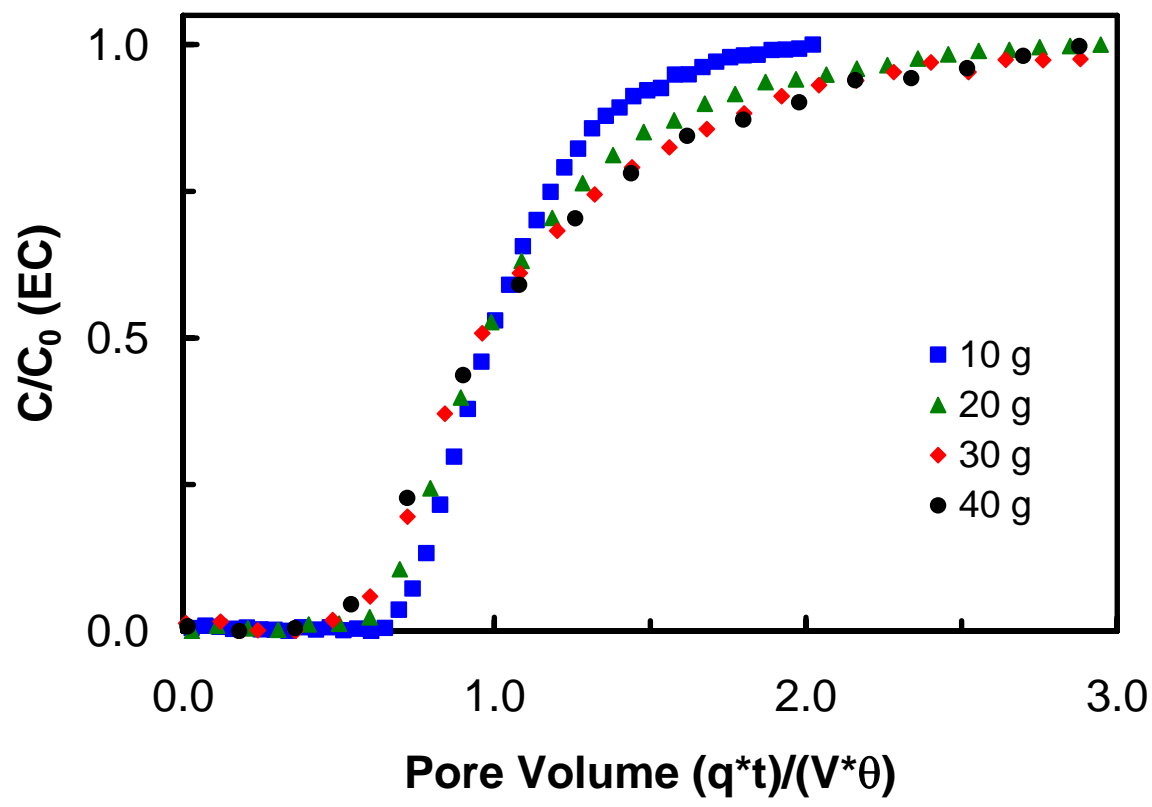

Figure 11. Comparison of relative concentration versus pore volume curves for 10, 20, 30 and 40-g column experiments. 


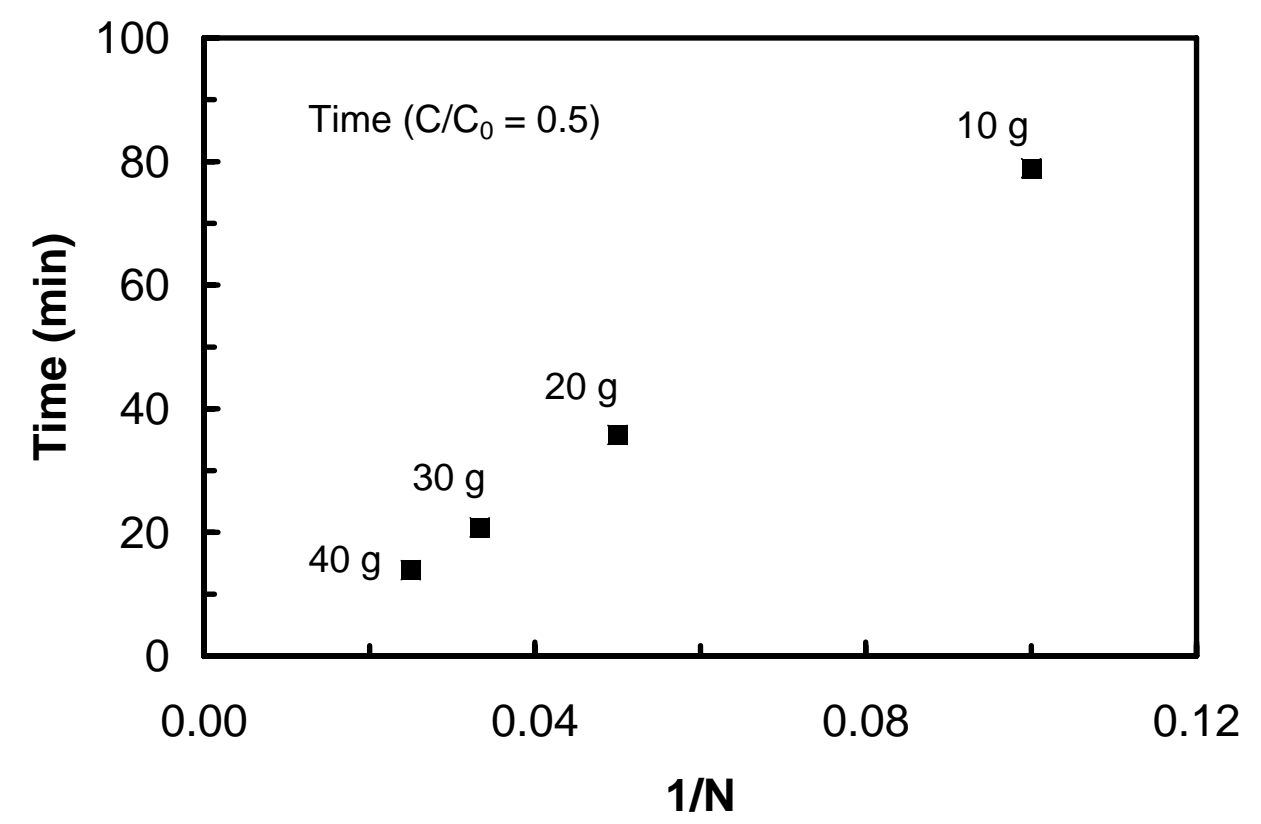

Figure 12. Mean breakthrough time (time at which $\mathrm{C} / \mathrm{C}_{0}=0.5$ ) as a function of $\mathrm{N}$.

by Culligan and Savvidou (1995) which was given as

$$
\mathrm{D}=\mathrm{D}_{\mathrm{m}}+\alpha \mathrm{Nv}
$$

where $D_{m}$ is the effective diffusion coefficient in the porous medium and $\alpha$ is the dispersivity. In our results the velocity is a linear function of $\mathrm{N}$, it follows that $\mathrm{D}$ varies with $\mathrm{N}^{2}$. A plot of $\mathrm{D}$ versus Nv (Figure 16) yields a straight line $\left(r^{2}=0.989\right.$; degrees of freedom $\left.=2\right)$ with slope $0.0836 \pm 0.0062 \mathrm{~cm}(\mathrm{t}=13.4, \mathrm{p}=0.0055)$ and an intercept that is not significantly different from zero (Intercept $=0.26 \pm 0.30 \mathrm{~cm}^{2} / \mathrm{min}, \mathrm{t}=0.085, \mathrm{p}=0.48$ ).

\section{Conclusion}

The expressions for the fluid potential, pressure, pressure head, and hydraulic head in a centrifugal field that we have developed (Palmer et al. 2003, 2005, in prep) serve as a basis for improved design and interpretation of experimental data. This theoretical foundation is also being used to adapt existing flow and transport codes to better simulate processes in a centrifugal field. The improved moisture probes, new fraction collector, and general experimental setups developed in this project represent significant advancements in the techniques needed to conduct 


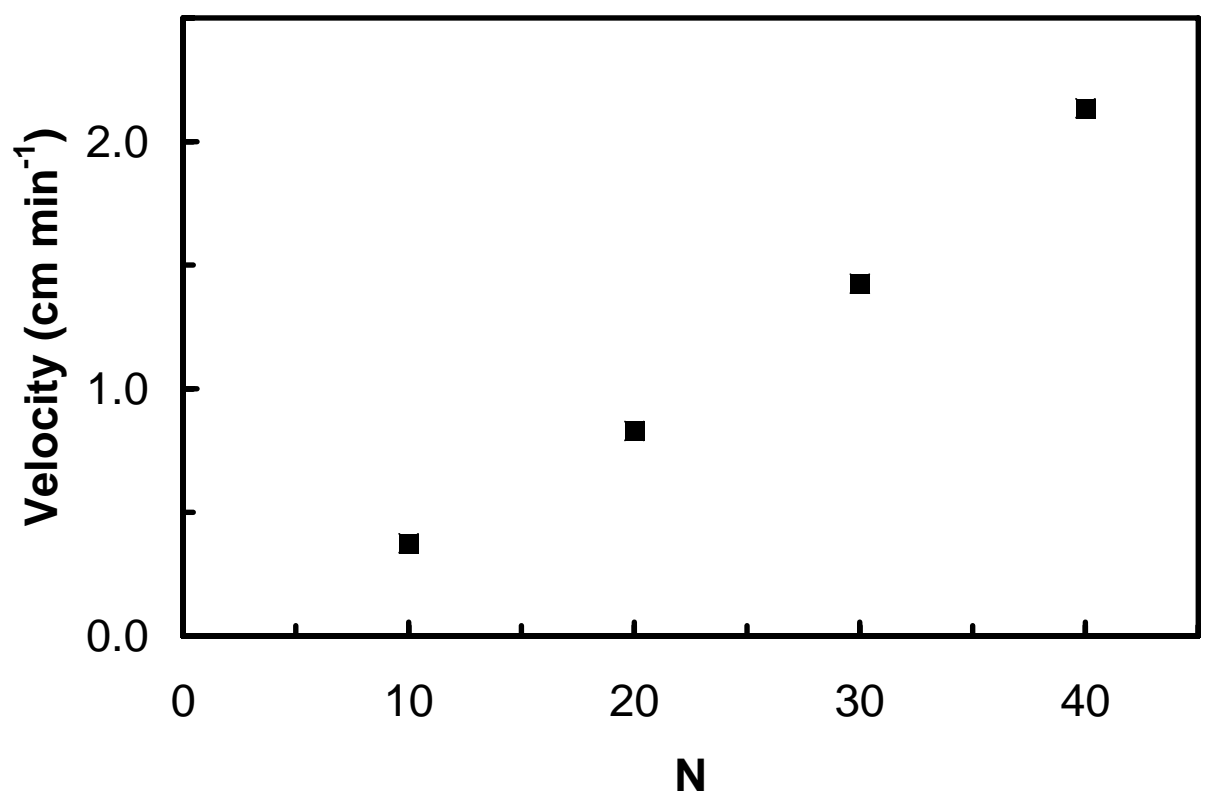

Figure13. Average pore water velocity as a function of N.

in-flight sampling and monitoring on the geocentrifuge. The data that we obtained indicate that the geocentrifuge technique is a viable experimental method for the study of subsurface processes where gravitational acceleration is important. The geocentrifuge allows experiments to be completed more quickly than tests conducted at 1-g, can be used to experimentally address important scaling issues, and permits experiments under a range of conditions that would be difficult or impossible using conventional approaches. The application of the geocentrifuge approaches and associated models developed in this project allows more meaningful investigation of DOE relevant vadose-zone issues under scalable conditions in time frames previously not obtainable.

\section{Acknowledgement}

This research was supported by the US Department of Energy’s Office of Biological and Environmental research through grant number DE-FG02-03ER63567. 


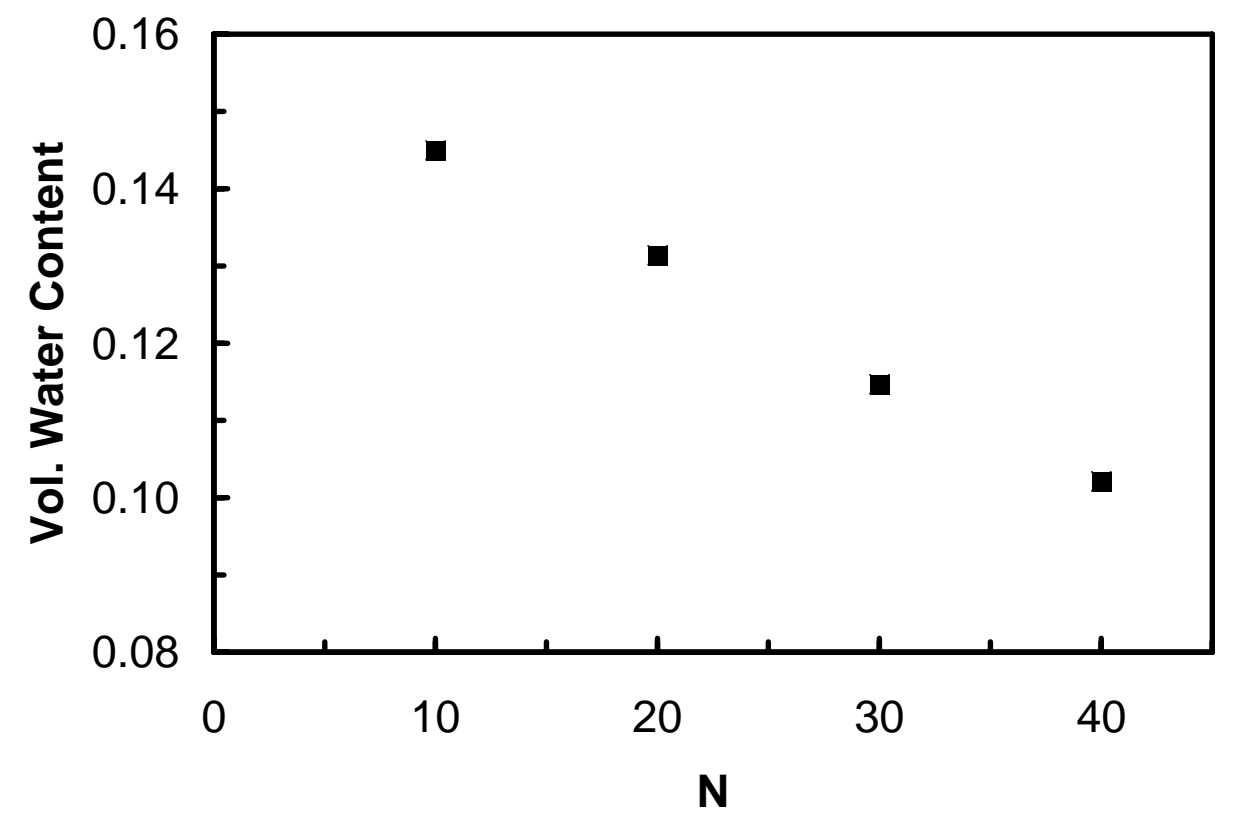

Figure 14. Moisture content as a function of N.

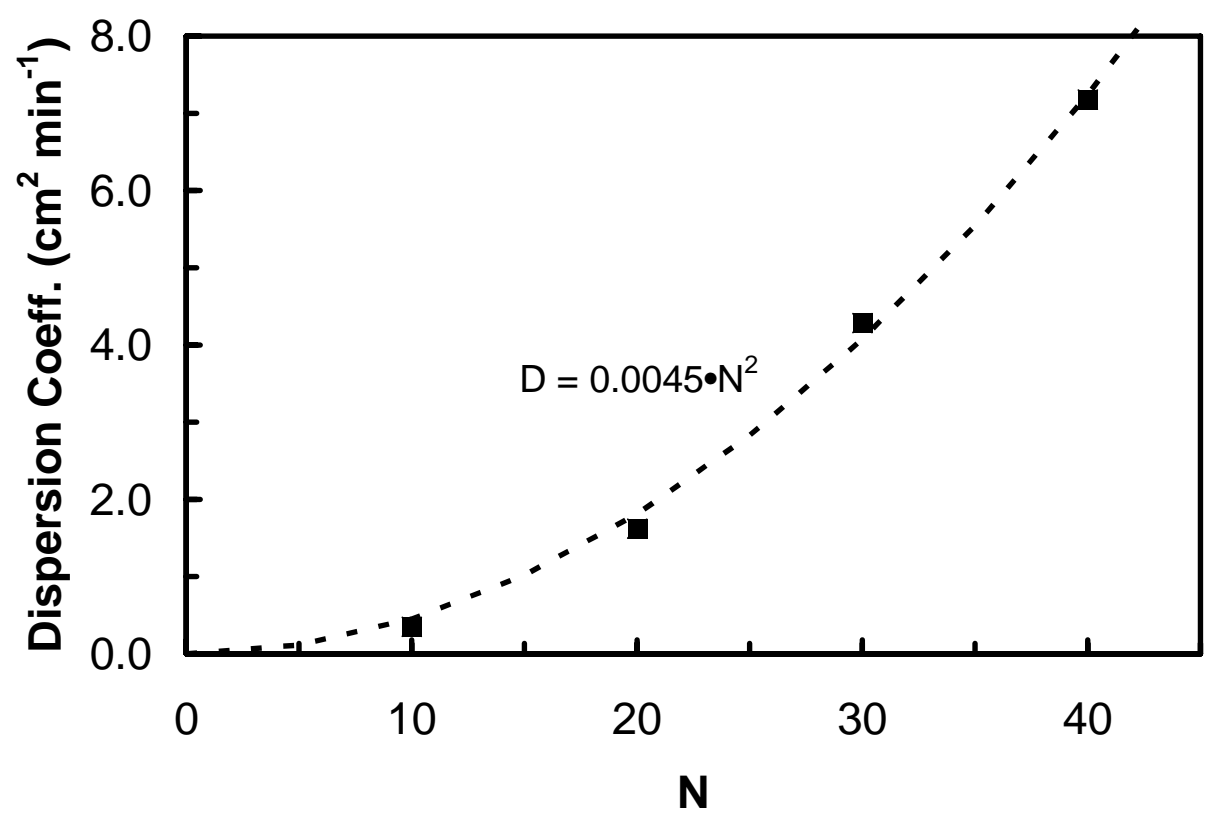

Figure 15. Dispersion Coefficient as a function of N. 


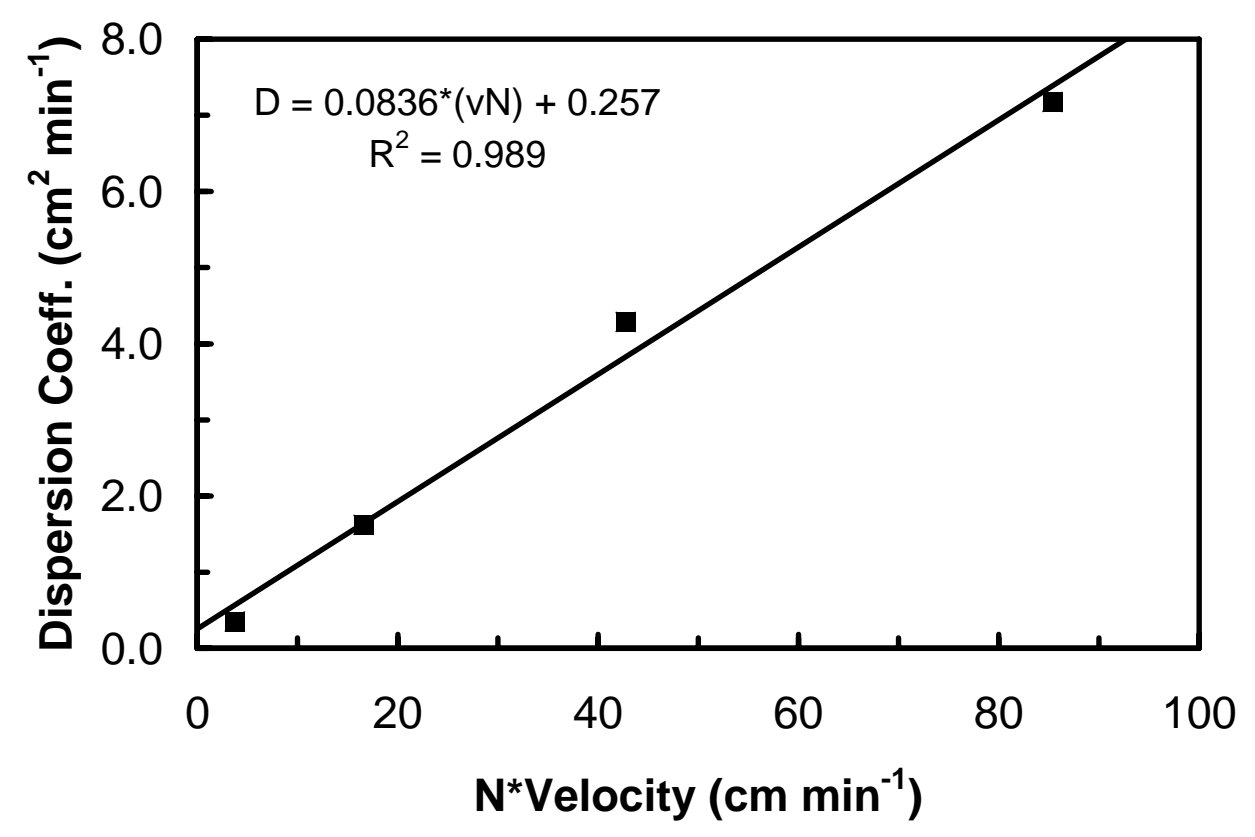

Figure 16. The relationship between scaled velocity and dispersion coefficient

\section{References}

Conca JL and Wright JV (1990) Diffusion coefficients in gravel under unsaturated conditions, Water Resour. Res., 26:1055-1066.

Conca JL and Wright JV (1998) The UFA Method for Rapid, Direct Measurements of Unsaturated Soil Transport Properties, Australian J. of Soil Research, 36:291-315.

Culligan-Hensley PJ and Savvidou C (1995) Environmental geomechanics and transport processes, in Geotechnical Centrifuge Technology, RN Taylor (ed.), Chapman and Hall, London, pp. 196-263.

Gamerdinger AP and Kaplan DI (2000) Application of a continuous-flow centrifugation method for solute transport in disturbed, unsaturated sediments and illustration of mobileimmobile water, Water Resour. Res., 36:1747-1755.

Jardine PM, Jacobs GK, and O’Dell JD (1993a) Unsaturated transport processes in undisturbed heterogeneous porous media: II. Co-contaminants, Soil Sci. Soc. Am. J. 57:954-962.

Jardine PM, Jacobs GK, and Wilson GV (1993b) Unsaturated transport processes in undisturbed heterogeneous porous media: I. Inorganic contaminants, Soil Sci. Soc. Am. J. 57:945953.

Mattson ED, Baker KE, Palmer CD, Breckenridge CR, Svoboda JM, and Smith RW (2006) A Flexible Water Content Probe for Unsaturated Soil Column Experiments, Vadose Zone Journal 5:805-808. 
Palmer CD, Crepeau J, and Smith RW (2003). Fundamental equations of flow in the geocentrifuge. Eos Trans. AGU, Fall Meet. Suppl. 84(46) Abstract H22A-0907.

Palmer CD, Crepeau J, Smith RW, and Mattson ED (2005) Fluid flow through porous media in a centrifugal field. Geological Society of America, Abstracts with Programs, 37(7) Paper No. 238-9, p. 523.

Palmer CD, Crepeau J, Smith RW, and Mattson ED, Equations of flow through porous media in a centrifugal field. In Preparation.

Taylor RN (1995) Centrifuges in modeling: principles and scale effects, in Geotechnical Centrifuge Technology, RN Taylor (ed.), Chapman and Hall, London, pp. 19-33.

Smith RW, Payne SJ, and Miller DL (2002) INEEL Environmental Geocentrifuge Facility Developments, in Physical Modeling in Geotechnics: ICPMG '02, R Phillips, PJ Guo, and R Popescu (eds), A.A. Balkema Publishers, Lisse, The Netherlands, pp. 55-58.

Wraith JM and Or D (1998) Nonlinear parameter estimation using spreadsheet software. J. Nat. Resour. Life Sci. Educ. 27:13-19. 


\section{Appendix A}

\section{Theoretical Considerations}

To fully realize the potential of centrifuge experimental techniques and the scaling approaches that can be taken, the similarity and differences of fluid flow in a centrifugal field and that of a constant 1gravity field must be understood. In geocentrifuge experiments conducted at low angular velocities such as those conducted in many geo-environmental applications, the gravitational force can be significant, yet it is often not included in the analysis of resultant data. Similarly, Coriolis accelerations are often assumed to be insignificant; we need to establish conditions under which these accelerations need to be explicitly included in the data analysis.

An expression for the fluid potential (energy per unit mass) for an incompressible fluid on the centrifuge in the local reference frame is derived. The expression includes terms for changes in potential energy of the fluid including centripetal acceleration, gravitational acceleration, and Coriolis acceleration as well as terms for changes is kinetic energy and the changes in the fluid pressure.

Based on this equation of the fluid potential, equations for specific discharge in orthotropic media in terms of equivalent pressure head $\left(\psi_{e}\right)$ and equivalent hydraulic head $\left(h_{e}\right)$ are derived. Using the height of the water column in the direction of gravitational acceleration as $\psi_{e}$ has several advantages including the lack of nonlinear terms, similarity to equations used in existing numerical codes, and a limiting form identical to Darcy's 1-g equation.

Nondimensionalization of the governing Navier-Stokes equations for porous media flows within a geocentrifuge shows the role of the Ekman and Rossby numbers and provides a dimensionless criterion for determining when the Coriolis term is negligible. The range of conditions under which Coriolis forces are most likely to be significant is illustrated in a plot of the maximum velocity at Coriolis forces become significant $\left(u_{\max }\right)$ as a function of $\omega$ for several radii associated with existing centrifuge systems (Figure A-1). Coriolis effects are inconsequential in granular materials smaller than fine sand, but they can be significant in coarse-grained material at high water contents and high angular accelerations (Figure A-2). Issues concerning the scaling of hydraulic conductivity and hydraulic gradient in the geocentrifuge are clarified. Our analysis provides information useful for the scaling of geocentrifuge experiments and helps to define the theoretical limits under which geocentrifuge experiments exhibit similarity to field phenomena. 


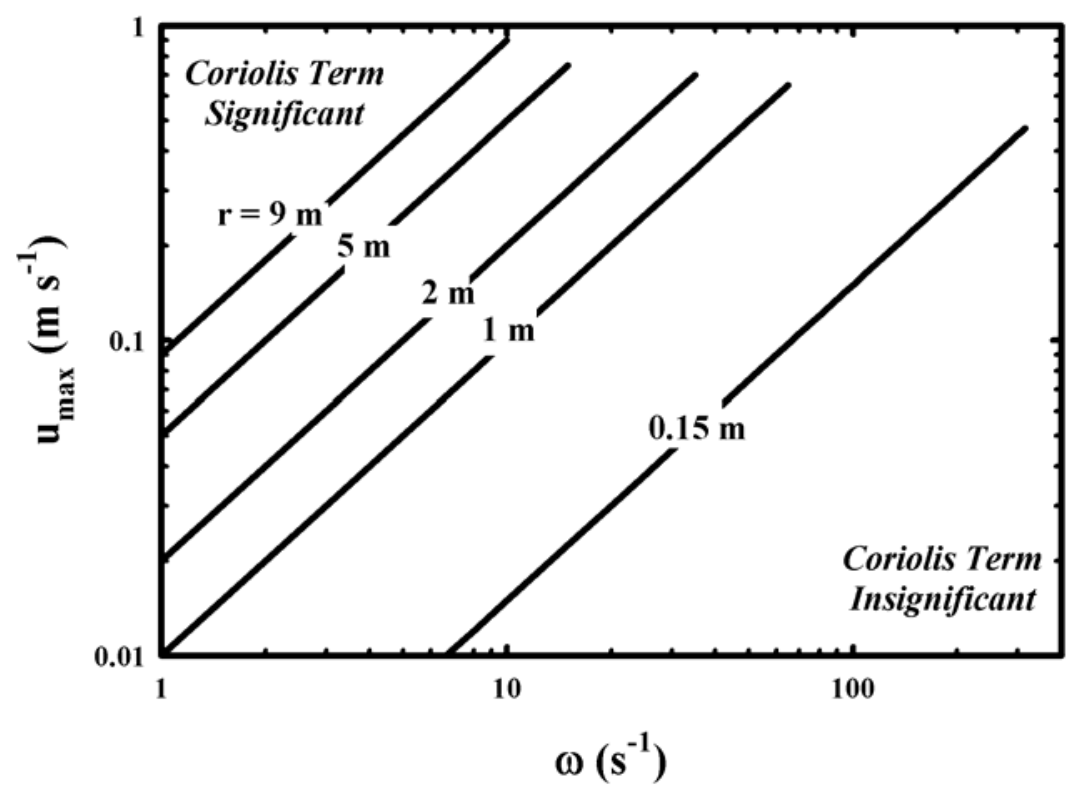

Figure A-1. Maximum fluid velocity at which Coriolis term is insignificant as a function of angular velocity and several radii.

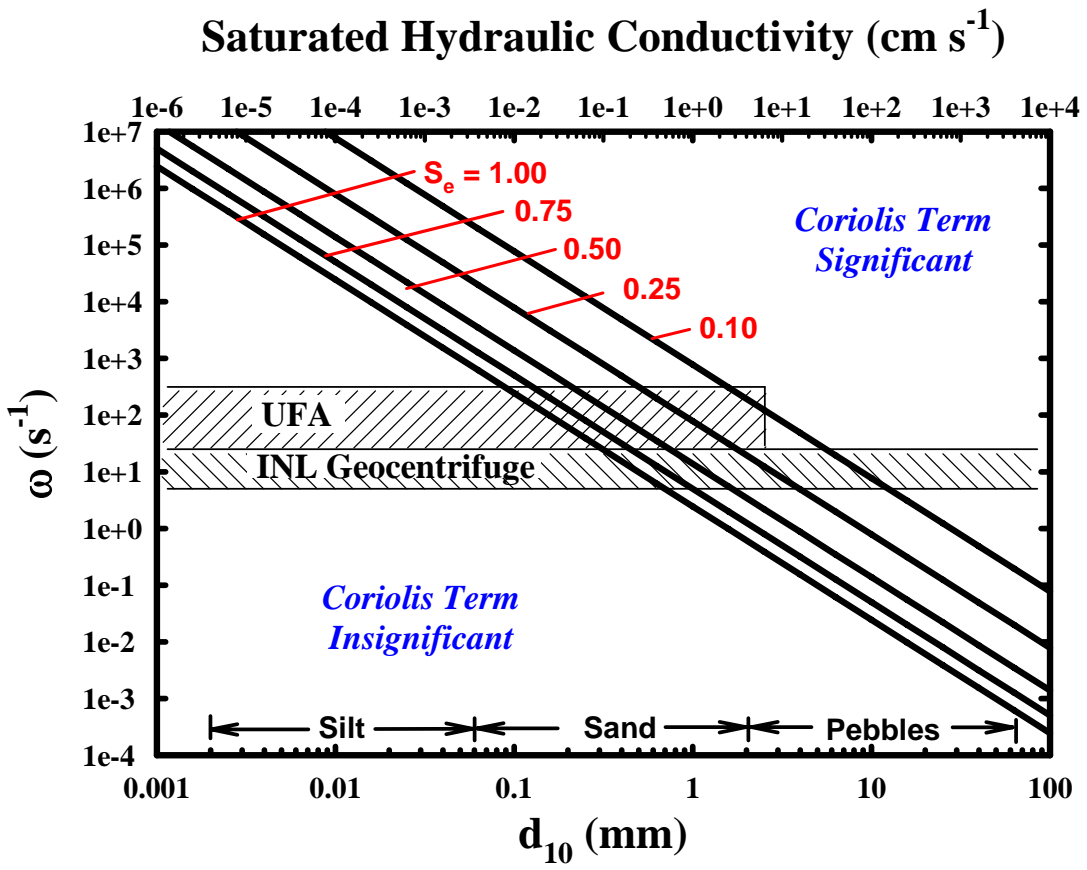

Figure A-2. Maximum angular acceleration at which the Coriolis term is insignificant as a function of the $d_{10}$ grain size or hydraulic conductivity. Calculation assumes $\theta_{\text {sat }}=0.25$ and the fraction of the centrifugal term considered to be significant is 0.02 . The area with hatch lines sloping to the left is the range of $d_{10}$ and $\omega$ that can be accommodated on the unsaturated flow apparatus (UFA) while the area with the hatch lines sloping to the right shows the range of parameters for the Idaho National Laboratory (INL) 2-m geocentrifuge. 